\title{
Correction to: Development and validation of an analytical model allowing accurate predictions of gamma and electron beam dose distributions in a water medical phantom
}

\author{
Safa Elj $^{1} \cdot$ Ahmed Ben-Ismail $^{1} \cdot$ Mohamed Slim Fayache ${ }^{1,2}$
}

Published online: 19 February 2021

○) Springer-Verlag GmbH Germany, part of Springer Nature 2021

Correction to: Radiation and Environmental Biophysics https://doi.org/10.1007/s00411-020-00877-4

Authors would like to correct the error in units from "meV" to "MeV" in their original publication of the article.

The original article has been corrected.

Publisher's Note Springer Nature remains neutral with regard to jurisdictional claims in published maps and institutional affiliations.

The original article can be found online at https://doi.org/10.1007/ s00411-020-00877-4.

Safa Elj

eljsafa@gmail.com

1 Laboratory on Energy and Matter for Nuclear Sciences Development, LR16CNSTN02, National Centre for Nuclear Sciences and Technologies, Sidi Thabet Technopark, 2020 Ariana, Tunisia

2 Department of Physics, Faculty of Sciences of Tunis, University of Tunis El Manar, 2092 Tunis, Tunisia 